\title{
Effect of target stenosis and location on radial artery graft patency
}

Hersh S. Maniar, MDa

Thoralf M. Sundt, MDa

Hendrick B. Barner, MD

Sunil M. Prasad, MDa

Linda Peterson, $M D^{b}$

Tarek Absi, MD

Pavlos Moustakidis, MDa

From the Divisions of Cardiothoracic Surgery $^{\mathrm{a}}$ and Cardiology, ${ }^{\mathrm{b}}$ Washington University School of Medicine, St Louis, Mo.

Read at the Eighty-first Annual Meeting of The American Association for Thoracic Surgery, San Diego, Calif, May 6-9, 2001.

Received for publication May 15, 2001; accepted for publication July 5, 2001.

Address for reprints: Thoralf M. Sundt, MD, Division of Cardiovascular Surgery, Mayo Clinic, 200 First St SW, Rochester, MN 55905.

J Thorac Cardiovasc Surg 2002;123:45-52

Copyright (c) 2002 by The American Association for Thoracic Surgery

$0022-5223 / 2002 \$ 35.00+0 \quad \mathbf{1 2 / 6 / 1 1 8 6 8 6}$

doi: $10.1067 / \mathrm{mtc} .2002 .118686$
Objective: The purpose of this study was to evaluate the effect of target vessel characteristics on radial artery patency when used as a composite $\mathrm{T}$ graft.

Methods: Between October 1993 and March 2001, 1022 patients underwent coronary bypass with the internal thoracic artery-radial artery composite $\mathrm{T}$ graft. Of these, angiography has been performed on 109 patients at a mean 27.1 months (range, 2-70 months) postoperatively for symptoms of ischemia. By means of Cox proportional hazard models, the relationships between anastomotic patency and target vessel location, proximal stenosis, target diameter, and quality were assessed.

Results: A total of 231 radial artery anastomoses were evaluated. The mean stenosis for patent anastomoses was $82 \%$ compared with $71 \%$ for occluded anastomoses $(P<.001)$. Anastomotic patency for targets with moderate stenosis $(\leq 70 \%)$ was worse than that for vessels with critical stenosis ( $\geq 90 \%$; relative risk, 1.7 ; $95 \%$ confidence interval, $1.3-2.2 ; P<.001)$. Patency for targets of the right coronary artery was statistically inferior to that for targets of the left anterior descending artery (relative risk, $1.8 ; 95 \%$ confidence interval, $1.2-2.9 ; P=.01)$ and bordered on significance versus that for the circumflex artery distribution (relative risk, 1.6; 95\% confidence interval, $1.0-2.8 ; P=.06$ ). When directed toward critically stenosed targets of the left anterior descending or circumflex arteries, radial artery patency was not statistically different that that of the internal thoracic artery $(P=.19)$.

Conclusion: Radial artery patency is sensitive to both target location and proximal target stenosis. Selective use of the radial artery to targets of the left anterior descending and circumflex distributions remains encouraging. Radial artery grafts to targets of the right coronary artery or those with moderate stenosis appear to be at particularly high risk of failure.

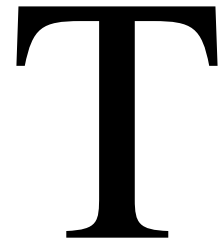

he long-term success of coronary artery bypass grafting remains dependent on continued graft patency. The internal thoracic artery (ITA) is the accepted conduit of choice for the left anterior descending artery (LAD), with improved patient survival associated with both single ${ }^{1,2}$ and bilateral ITA grafting. ${ }^{3,4}$ These results suggest that further benefit may be gained from a strategy of total arterial revascularization. ${ }^{5,6}$ Tector and associates ${ }^{7}$ have demonstrated that 2 ITAs, when used as a composite $\mathrm{T}$ graft, can successfully provide a total arterial revascularization for the majority of patients with triple-vessel disease. Alternatives to the use of bilateral ITA grafting are desirable, particularly for patients with diabetes, obstructive lung disease, or obesity, because their risk of sternal infection may be increased with this approach. ${ }^{8}$ 
TABLE 1. Patient characteristics

\begin{tabular}{lc}
\hline Patient profile (n = 109) & Value \\
\hline Sex (M/F) & $69 / 49$ \\
Age (y) & $58 \pm 10.1$ \\
Comorbidities & \\
Diabetes & $32 \%$ \\
Smoking & $54 \%$ \\
Hypertension & $60 \%$ \\
Hypercholesteremia* & $44 \%$ \\
Cerebrovascular disease & $13 \%$ \\
Peripheral vascular disease & $14 \%$ \\
Renal failure & $2 \%$ \\
NYHA classification & \\
Class I & $2 \%$ \\
Class II & $50 \%$ \\
Class III & $26 \%$ \\
Class IV & $22 \%$ \\
Previous myocardial infarction & $48 \%$ \\
Ejection fraction $<35 \% \dagger$ & $10 \%$
\end{tabular}

NYHA, New York Heart Association.

*Data available for 61 patients.

tData available for 98 patients.

Recently, the radial artery (RA) has gained popularity as an alternative conduit for coronary bypass grafting. It may be used either as an aorta-coronary graft or as a composite $\mathrm{T}$ graft when anastomosed proximally to the pedicled ITA. The RA is an attractive conduit because it can be harvested simultaneously with the ITA and may be taken bilaterally if additional conduit is required. Its thick vessel wall and large diameter facilitate the performance of anastomoses, and its length is sufficient to accommodate sequential grafting for even distal targets. ${ }^{9}$ As a result of its versatility, the RA has become the second conduit of choice after the ITA for many surgeons. ${ }^{8}$

The reported early patency for the RA is promising, ${ }^{10-12}$ but late patency and factors affecting it have yet to be established. Some evidence suggests that the RA may be particularly sensitive to competitive flow. ${ }^{13}$ Furthermore, the effect of target location and coronary size are both factors that have been shown to influence vein graft patency, but neither have been investigated for the RA. The purpose of this study was to evaluate the effect of target location, proximal stenosis of the target vessel, target size, and quality on the composite ITA-RA T-graft patency.

\section{Methods}

\section{Study Population}

Between October 1993 and March 2001, 1022 patients underwent coronary artery bypass grafting with the RA and ITA in a composite T-graft configuration. Of these, 109 patients underwent postoperative angiography for signs or symptoms of myocardial ischemia. These patients constituted the study population. Patient demographics, comorbidities, and perioperative (30-day) outcome
TABLE 2. RA target characteristics

\begin{tabular}{lr}
\hline Variable (n = 233) & No. \\
\hline Target distribution & \\
Left anterior descending coronary artery & \\
$\quad$ Left anterior descending (proper) & 4 \\
Ramus & 9 \\
Diagonal & 17 \\
Circumflex coronary artery & \\
Obtuse marginal & 92 \\
Left posterolateral & 10 \\
Right coronary artery & \\
$\quad$ Posterior descending & 79 \\
Right posterolateral & 22 \\
Proximal stenosis (\%) & \\
Moderate (0\%-70\%) & 90 \\
Severe (71\%-89\%) & 48 \\
Critical (90\%-100\%) & 95 \\
Coronary diameter (mm) & \\
$\quad<1.0$ & 0 \\
1-1.5 & 134 \\
>1.5 & 98 \\
Target quality & \\
Good & 186 \\
Pair & 47 \\
\hline & 000 \\
\hline
\end{tabular}

data were collected prospectively in accordance with the Society of Thoracic Surgeons database guidelines (Table 1). All data were collected under the guidelines of the institutional review board, and informed consent was obtained from each participant.

Target vessel characteristics were prospectively recorded (Table 2). Target vessels were classified as moderately $(\leq 70 \%)$, severely $(71 \%-89 \%)$, or critically ( $\geq 90 \%)$ stenosed, as determined by the results of preoperative angiography. The operating surgeon recorded target vessel location, size, and quality in the operative record. Target locations were classified as the LAD, circumflex artery, or right coronary artery (RCA) on the basis of their anatomic relation to the major coronary arteries. Target quality was characterized as good or fair on the basis of the extent of local atherosclerotic disease at the anastomotic site.

\section{Patient Selection}

Although originally reserved for younger patients or in instances of limited conduit availability, the composite $\mathrm{T}$ graft has become the coronary grafting strategy of choice in patients of less than 80 years of age at this institution. Adequate collateral circulation of the hand was assessed by the modified Allen test. Capillary refill within 10 seconds was considered acceptable. Occasionally, Doppler ultrasonography or pulse plethysmography was used when questions regarding sufficient collateral circulation remained.

\section{Grafting Strategy}

During this study, the ITA was routinely used for the LAD and was frequently used as a sequential graft to the diagonal artery. The RA was used as a composite graft in all cases and anastomosed prox- 
imally to the ITA. The RA was directed most often to targets of the circumflex artery and RCA distributions (Table 2), with sequential grafting performed routinely to provide total arterial revascularization. Rarely, when total arterial grafting was not possible because of geometry or limited conduit length, additional saphenous vein grafts were used.

\section{RA Harvesting and Preparation}

A surgical assistant harvested the RA simultaneously with the harvest of the ITA. The details of this procedure have been previously described. ${ }^{14}$ Briefly, the RA and its surrounding venous structures were dissected sharply as a pedicle, without use of electrocautery. More recently, the Harmonic scalpel (Ethicon Endo-Surgery, Inc, Cincinnati, Ohio) has been used for this dissection. The RA was stored in diluted papaverine $(60 \mathrm{mg}$ of papaverine in $30 \mathrm{~mL}$ of heparinized blood) before the ITA anastomosis. The completed T graft was filled with the same solution and allowed to distend under arterial pressure while we were preparing for initiation of cardiopulmonary bypass. No mechanical or hydrostatic methods of dilatation were used, so that intimal injury could be avoided. ${ }^{14}$

\section{Surgical Technique}

Two surgeons familiar with the T-graft strategy performed all procedures according to the surgical technique that has been previously described. ${ }^{14}$ Cardiopulmonary bypass and cardioplegic cardiac arrest were used for all cases. The ITA was harvested as a pedicled graft for all patients. The RA anastomosis was performed end to side at the level at which the ITA enters the pericardial space and adjacent to the left atrial appendage. The RA was fish mouthed and taken from the ITA as a T or Y graft at approximately $45^{\circ}$. All side-to-side anastomoses were performed in a parallel fashion.

\section{Pharmacologic Protocol}

Systemic calcium-channel blockers (nicardipine) were administered intraoperatively and for the first 24 hours postoperatively. Oral calcium-channel blockers (diltiazem or nicardipine) were prescribed for the first 6 months postoperatively but were frequently discontinued by the patient or referring physician.

\section{Follow-up}

The clinical research staff obtained follow-up data for 1022 patients with an ITA-RA T graft between July 1998 and April 2001 by means of postal questionnaires and telephone interviews. A total of 109 patients were identified as having undergone postoperative angiography or subsequent cardiac intervention. The results of postoperative angiography were obtained directly from the performing cardiologist or cardiac catheterization laboratory. Anastomotic failure was defined as occlusion or stenosis of $90 \%$ or greater. The presence of extensive conduit narrowing or "string sign" was considered functionally occluded and recorded as nonpatent.

\section{Statistical Analysis}

Statistical analysis was conducted with SAS version 7.0 software (SAS Institute, Inc, Cary, NC). Survival analysis methods were based on the incidence of anastomotic failure that was presumed to occur at the time of reangiography. Kaplan-Meier analysis was used for comparisons of RA and ITA patencies. Univariate analy-
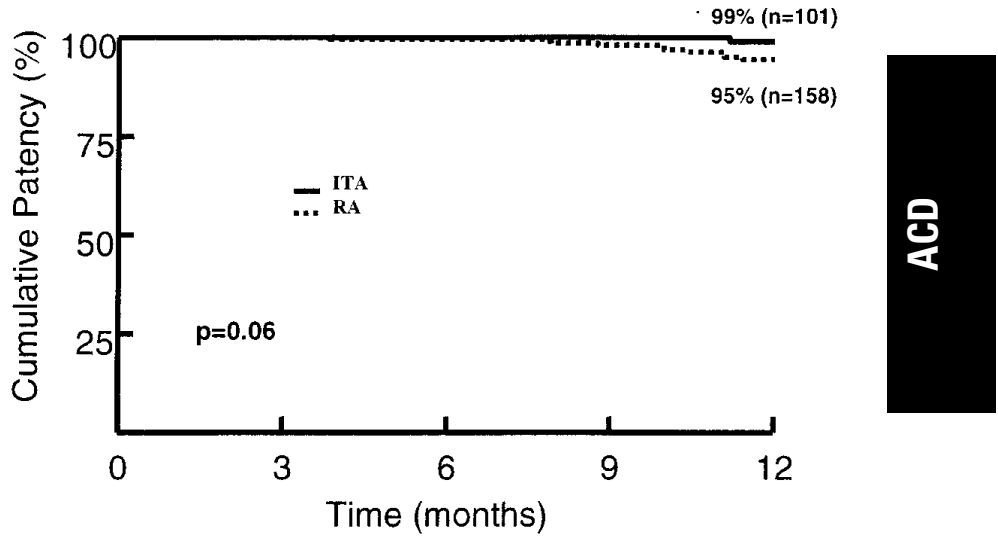

Figure 1. Early cumulative patency of RA versus ITA grafts to all targets up to 1 year postoperatively.

sis identified target variables that were significantly associated with RA anastomotic failure. Multivariate analysis with Cox regression identified the relative risks and $95 \%$ confidence intervals (CIs) for significant target variables on the basis of the $\chi^{2}$ statistic. Continuous data were expressed as means \pm SD unless otherwise stated. All statistical analyses were reviewed by the Department of Biostatistics, Washington University, and are in agreement with the "Uniform Requirements for Manuscripts Submitted to Biomedical Journals According to Biostatistics" guidelines.

\section{Results}

The mean follow-up time was 27.1 months (range, 2-70). Among 109 RA conduits available for study, sequential grafting was performed in $90.8 \%$ of RA grafts, resulting in 233 distal anastomoses. Postoperative angiographic data were incomplete for 1 patient, resulting in 231 distal RA anastomoses available for evaluation. The ITA portion of the $T$ graft $(n=109)$ provided 144 distal ITA anastomoses for which patency data were available.

Early patencies for the RA and ITA to all targets were $95 \%$ and $99 \%$ at 12 months, respectively (Figure 1). The number of anastomotic failures for the RA $(n=8)$ versus those for the ITA $(n=1)$ during this interval bordered on significance, as determined with Kaplan-Meier analysis. The first instance of anastomotic failure occurred at 3.8 months for the RA group and at 11.1 months for the ITA. The difference in anastomotic failures for the RA $(n=19)$ and the ITA $(n=3)$ did become statistically different at 18 months postoperatively, as determined by means of actuarial analysis $(P=.015)$.

Analysis of the effect of target quality and diameter was complicated by uneven distribution of numbers of anastomoses within the groups (Table 2). The majority of all RA targets were of larger size. There were significantly fewer targets that were less than $1.5 \mathrm{~mm}$ in size $(P<.001)$, and no targets that were less than $1 \mathrm{~mm}$ in diameter. 


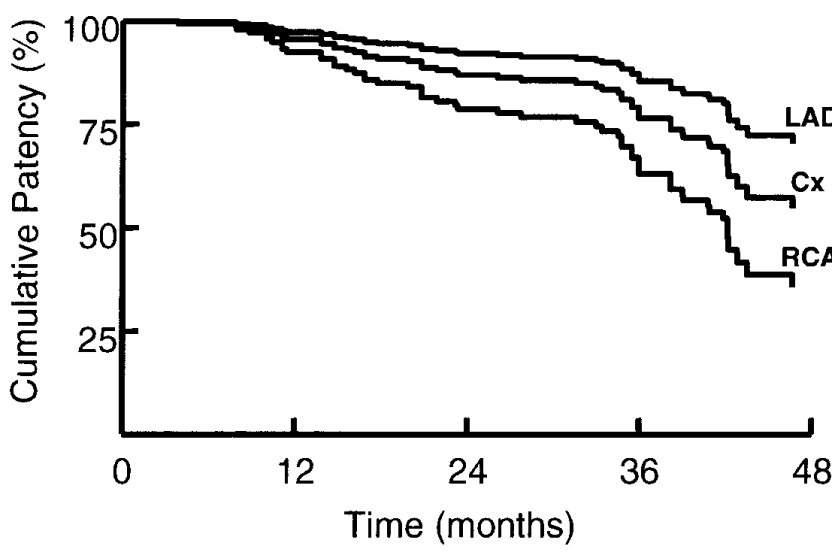

Figure 2. Cumulative patency for RA anastomotic locations. There was an increase in the risk of graft failure associated with nonLAD targets. The relative risks for the targets of the RCA were statistically significant versus those of the LAD (relative risk, 1.8; 95\% CI, 1.15-2.94; $P=.01$ ) and bordered on significance versus those of the circumflex artery $(C x$, relative risk, 2.08 ; $95 \% \mathrm{CI}, 0.78$ 5.55; $P=.06)$.

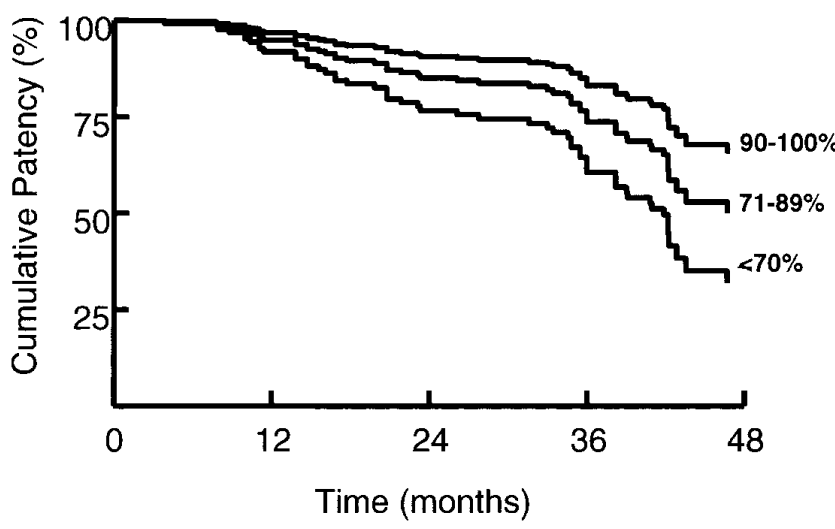

Figure 3. Cumulative RA patency associated with proximal target stenosis: moderately stenosed vessels with a significant increase in anastomotic failure versus critically stenosed targets (relative risk, 1.69; 95\% Cl, 1.25-2.20; $P<$.001).

Similarly, the majority of targets were characterized as good quality, with significantly fewer anastomoses to targets of fair quality $(P<.001)$. No targets were characterized as poor quality or with extensive local disease.

Target location and stenosis were both identified as significant predictors for anastomotic failure. As shown in Table 3, univariate analysis demonstrated superior patency for targets of the LAD and progressively worse patency for the circumflex and RCA distributions. The effect of coronary distribution on graft patency, independent of proximal stenosis, was examined within a Cox multivariate analysis (Table 4). Target location as an independent variable
TABLE 3. Univariate analysis of risk factors for graft occlusion

\begin{tabular}{lcc}
\hline Variable & Patency & Pvalue \\
\hline Location & & .02 \\
$\quad$ Left anterior descending & $83.3 \%$ & \\
$\quad$ Circumflex & $75.2 \%$ & \\
$\quad$ Right coronary artery & $72.7 \%$ & \\
Stenosis & & $<.01$ \\
$\quad$ Critical & $83.0 \%$ & \\
$\quad$ Severe & $68.8 \%$ & \\
$\quad$ Moderate & $57.3 \%$ & \\
Coronary artery diameter & & .62 \\
$\quad 0-1.5$ & $75.0 \%$ & \\
$\quad>1.5$ & $64.3 \%$ & \\
Target quality & & .67 \\
$\quad$ Good & $68.6 \%$ & \\
Fair & $76.1 \%$ & \\
\hline
\end{tabular}

TABLE 4. Multivariate analysis of risk factors

\begin{tabular}{lclccc}
\hline Variable & Reference & Index & RR & 95\% CI & Pvalue \\
\hline Target location & LAD & Cx & 2.08 & $0.78-5.55$ & .14 \\
& & RCA & 1.84 & $1.15-2.94$ & .01 \\
Target stenosis (\%) & $\geq 90$ & $71-89$ & 1.80 & $0.85-3.8$ & .12 \\
& & $\leq 70$ & 1.69 & $1.25-2.20$ & $<.001$ \\
\hline
\end{tabular}

$R R$, Relative risk; $C l$, confidence interval; $L A D$, left anterior descending; $C x$, circumflex artery; $R C A$, right coronary artery.

remained a significant predictor for RA patency. The risk of anastomotic failure on the basis of target choice was increased for vessels of both the circumflex and right coronary distributions. The increased risk for anastomotic failure was statistically significant for targets of the RCA and almost 2-fold higher than for targets of the LAD. The isolated effects of target location are shown in Figure 2. The actuarial curves for anastomoses to targets of the LAD and the circumflex artery both demonstrated superior patency when compared with targets of the RCA.

RA patency was similarly affected by proximal target stenosis. Actuarial patency for the RA was lowest for vessels with moderate stenosis $(\leq 70 \%)$ and increased steadily with increasing target stenosis (Table 3). A similar trend was demonstrated within a multivariate analysis. The effect of proximal target stenosis adjusted for any confounding effects caused by target location is shown in Figure 3 . Patency for moderately stenosed vessels was inferior to that of both severe and critically stenosed targets. The inferior patency for vessels with $70 \%$ or less stenosis (moderate) was statistically significant when compared with that of vessels with $90 \%$ stenosis or higher. The increased relative risk for anastomotic failure (Table 4) was also significant 


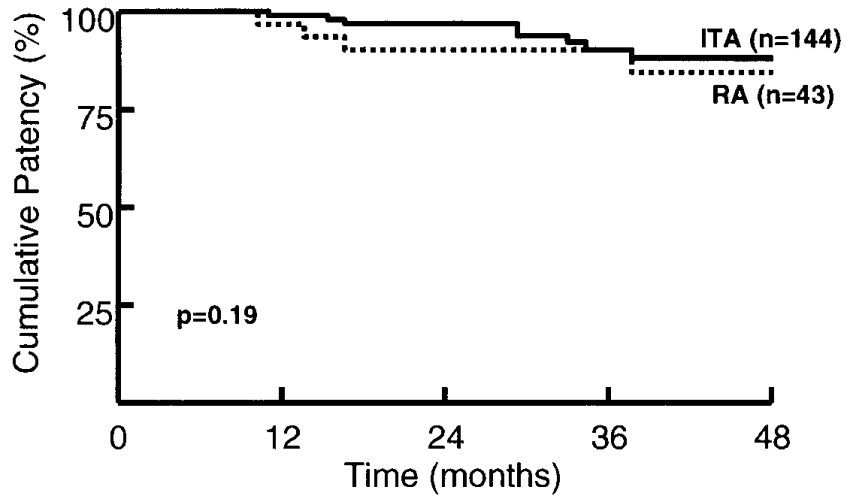

Figure 4. Kaplan-Meier analysis of RA patency for optimal targets: critically stenosed targets of left circulation. No significant difference was seen between RA and ITA patency $(P=.19)$.

for the group of moderately stenosed targets ( $\leq 70 \%$ stenosis). The average target stenosis for patent vessels was $82.2 \% \pm 15.2 \%$ compared with $70.9 \% \pm 17.7 \%$ for occluded vessels $(P<.001)$.

In an effort to demonstrate the optimum patency for the RA, the patencies of the RA to "best" and "worst" targets were determined. The patency of the RA when used for critically stenosed targets of the LAD or circumflex distributions $(n=43)$ was excellent and not statistically different than the patency to the ITA (Figure 4). The patency of anastomoses to targets of the RCA with moderate stenosis (Figure 5), however, was dramatically different. RA patency in this setting was only $26 \%$ at 4 years and significantly worse than ITA patency at the same interval.

\section{Discussion}

The principal finding of this investigation is that both coronary target location and the extent of proximal stenosis affect RA anastomotic patency. RA patency was best when grafted to the LAD distribution and significantly worse when placed to targets of the RCA distribution. Target location has previously been shown to be an important factor in anastomotic patency for both venous and ITA conduits. Huddleston and colleagues ${ }^{15}$ demonstrated superior patency for the ITA when grafted to the LAD versus to nonLAD targets. Similarly, Paz and associates ${ }^{16}$ have demonstrated higher patency for saphenous vein grafts when preferentially grafted to the LAD as opposed to other coronary targets. The large mass of myocardium supplied by the LAD and its branches is thought to result in superior outflow and hence superior graft patency. ${ }^{17}$ Presumably, the smaller vascular bed associated with the RCA distribution accounts for its relatively poor patency, as observed in several series examining vein graft patency. ${ }^{16,18}$ Buxton and associates $^{19}$ have also recently reported worse patency for

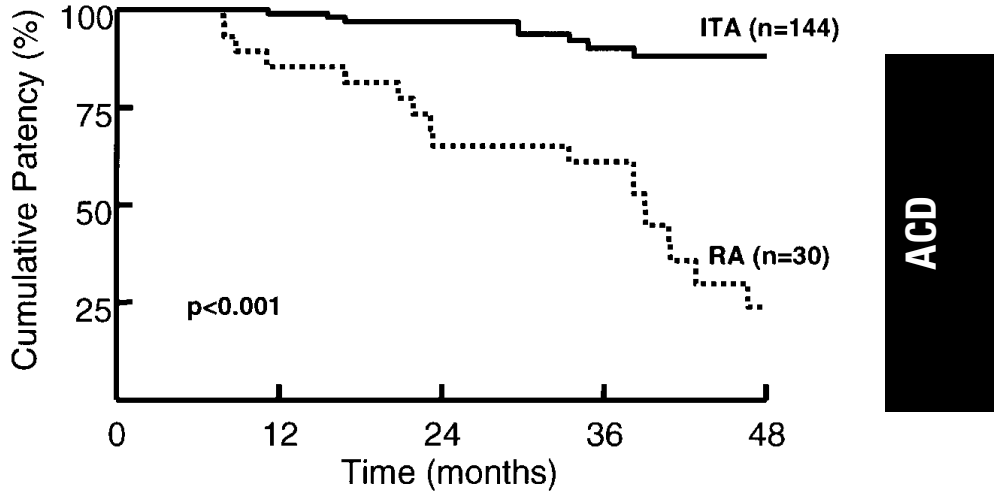

Figure 5. Kaplan-Meier analysis of RA patency for suboptimal targets: moderately stenosed vessels of the RCA. RA patency was significantly inferior versus ITA patency, with only $26 \%$ of anastomoses patent at 48 months $(P<.001)$.

the right ITA grafts to RCA targets compared with patencies of targets to the left system.

In this investigation RA graft patency was also significantly inferior when grafted to moderately stenosed coronary vessels. Presumably, this is secondary to competitive flow. Several investigators have demonstrated an association between grafting moderately stenosed vessels and a subsequent increase in the incidence of arterial graft occlusion or an angiographic "string sign."20,21 Angiographically, a to-and-fro pattern of flow is often seen within bypass conduits when anastomoses are performed to less than critically stenosed vessels. This oscillating flow between native and conduit circulations produces greater shear force on conduit endothelium and may predispose to an anastomotic occlusion. ${ }^{22}$

Among arterial conduits, the RA may be particularly sensitive to competitive flow given its increased propensity for graft spasm. ${ }^{23}$ Tatoulis and colleagues ${ }^{8}$ reported RA patency that decreased significantly from $94 \%$ to $72 \%$ when grafted to vessels with less than $70 \%$ native disease. Possati and associates $^{24}$ have demonstrated a similar increase in RA graft occlusion when anastomosed to less than critically stenosed vessels. Some surgeons have further recommended that the RA be reserved for grafting only the relatively greater stenosed coronary targets to avoid the effects of competitive flow. ${ }^{13,25}$ Among 12 patients from within this study, the proximal segment of the RA graft, extending from the ITA to the first distal anastomosis, was occluded; however, the distal segment remained patent. Coronary-to-coronary flow was apparent angiographically. The flow was typically from the circumflex system to the RCA, although occasionally retrograde flow was evident. This coronary autoperfusion supports the concept of competitive flow leading to graft occlusion rather than technical difficulties at the anastomoses.

Neither the variation in coronary artery size nor the extent of atherosclerosis at the anastomotic site (target qual- 
ity) was found to be significantly associated with RA graft patency (Table 3). Although both variables have been shown to be significant predictors for anastomotic failure in other studies, ${ }^{16}$ the statistical analysis in this investigation was hindered by the uneven distributions within the target size and target quality groups.

This investigation supports the safety of the proximal anastomosis of the RA to the ITA in the T-graft configuration. Construction of the ITA-RA composite graft is more technically challenging than an anastomosis to the aorta. However, the concern that technical errors of this anastomosis may endanger the ITA conduit and the resulting anastomosis to the LAD was not borne out in this study. The demonstrated ITA patency was excellent, indicating that the ITA was not adversely affected by the $T$ anastomosis. The low operative mortality observed previously by us ${ }^{6}$ and oth$\operatorname{ers}^{26,27}$ further supports the safety of this technique when performed carefully.

In summary, RA patency is sensitive to both the location and proximal stenosis of the bypassed coronary artery. On the basis of these data, we have modified our approach to coronary revascularization. The effect of target vessel location, although disappointing for the RCA, is not different than for other conduits. Although the risk of anastomotic failure is higher for RCA targets than for others, the patency of the RA is likely to be as good as or better than that of other conduits given high-grade proximal disease. We therefore continue to use the RA for the critically stenosed RCA target.

The management of targets with moderate native disease is more problematic. We have abandoned the use of the RA to targets with moderate stenosis because we believe other conduits may perform better. Reserving the RA for targets with higher stenosis seems appropriate, and when selectively used, the RA remains promising as an alternative arterial conduit. ${ }^{13}$ The relative degrees to which the ITA and RA resist competitive flow are unknown and worthy of further investigation. Furthermore, although prospective randomized trials are not available, the conventional wisdom is that high-flow saphenous grafts may better compete with the native circulation and be less susceptible to competitive flow. Alternatively, the ability of cardiologists to slow the progression of native disease and the option of subsequent percutaneous intervention opens the discussion of leaving moderately stenosed targets ungrafted. We discuss each of these cases individually with all physicians involved when making this decision.

The principal limitation of this study is that it is retrospective and influenced by patient selection and grafting strategy. This study was conducted in a highly selected group of symptomatic patients with signs or symptoms of ischemia. This represents a worst-case scenario in the analysis of RA patency. It has been long recognized that graft patency may be $15 \%$ to $20 \%$ lower among sympto- matic versus asymptomatic patients. ${ }^{28}$ The data concerning relative patency, however, should be minimally affected by this consideration, and conclusions regarding risk factors for anastomotic failure should remain valid.

An additional limitation is imposed by the assumption that the time to graft failure is assumed to be the same as the date of postoperative cardiac catheterization. In the absence of serial follow-up angiography, this assumption permits the use of the Cox model for analysis of patency within a longitudinal study.

This article would not have been possible without the dedicated efforts of the clinical research staff and their tireless commitment to patient follow-up.

\section{References}

1. Cameron A, Davis KB, Green G, Schaff HV. Coronary bypass surgery with internal-thoracic-artery grafts-effects on survival over a 15-year period. N Engl J Med. 1996;334:216-9.

2. Loop FD, Lytle BW, Cosgrove DM, Stewart RW, Goormastic M, Williams GW, et al. Influence of the internal-mammary-artery graft on 10-year survival and other cardiac events. N Engl J Med. 1986;314:1-6.

3. Fiore AC, Naunheim KS, Dean P, Kaiser GC, Pennington G, Willman VL, et al. Results of internal thoracic artery grafting over 15 years: single versus double grafts. Ann Thorac Surg. 1990;49:202-9.

4. Lytle BW, Blackstone EH, Loop FD, Houghtaling PL, Arnold JH, Akhrass R, et al. Two internal thoracic artery grafts are better than one. J Thorac Cardiovasc Surg. 1999;117:855-72.

5. Tector AJ, Schmahl TM, Canino VR. Expanding the use of the internal mammary artery to improve patency in coronary artery bypass grafting. J Thorac Cardiovasc Surg. 1986;91:9-16.

6. Sundt TM, Barner HB, Camillo CJ, Gay WA. Total arterial revascularization with an internal thoracic artery and radial artery T graft. Ann Thorac Surg. 1999;68:399-405.

7. Tector AJ, Kress DC, Schmahl TM, Amundsen S. T-graft: a new method of coronary arterial revascularization. J Cardiovasc Surg. 1994;35(Suppl 1):19-23.

8. Tatoulis J, Buxton BF, Fuller JA, Royse AG. The radial artery as a graft for coronary revascularization: techniques and follow-up. In: Karp RB, Laks H, Wechsler AS, editors. Advances in cardiac surgery. Vol 11. St Louis: Mosby; 1999. p. 99-128.

9. Calafiore AM, Di Giammarco G, Luciani N, Maddestra N, Di Nardo E, Angelini R. Composite arterial conduits for a wider arterial myocardial revascularization. Ann Thorac Surg. 1994;58:185-90.

10. Brodman RF, Frame R, Camacho M, Hu E, Chen A, Hollinger I. Routine use of unilateral and bilateral radial arteries for coronary artery bypass graft surgery. J Am Coll Cardiol. 1996;28:959-63.

11. Tatoulis J, Buxton BF, Fuller JA, et al. The radial artery in coronary surgery: a 5 year experience-clinical and angiographic results. Ann Thorac Surg. In press.

12. Acar C, Jebara VA, Portoghese M, Beyssen B, Pagny JY, Grare P, et al. Revival of the radial artery for coronary artery bypass grafting. Ann Thorac Surg. 1992;54:652-60.

13. Calafiore AM, Di Giammarco G, Teodori G, D’Annunzio E, Vitolla G, Fino C, et al. Radial artery and inferior epigastric artery in composite grafts: improved midterm angiographic results. Ann Thorac Surg. 1995;60:517-24.

14. Barner HB. Defining the role of the radial artery. Semin Thorac Cardiovasc Surg. 1996;8:3-9.

15. Huddleston CB, Stoney WS, Alford WC, Burrus GR, Glassford DM, Lea JW. Internal mammary artery grafts: technical factors influencing patency. Ann Thorac Surg. 1986;42:543-9.

16. Paz MA, Lupon J, Bosch X, Pomar JL, Sanz G, GESIC study group. Predictors of early saphenous vein aortocoronary bypass graft occlusion. Ann Thorac Surg. 1993;56:1101-6. 
17. Mehta J, Hamby RI, Aintablian A, Hoffman I, Hartstein ML, Wisoff BG, et al. Preoperative coronary angiographic prediction of bypass glow and short-term patency. Cathet Cardiovasc Diagn. 1975;1:381-8.

18. Lytle BW, Loop FD, Cosgrove DM, Ratliff NB, Easley K, Taylor PC. Long-term (5 to 12 years) serial studies of internal mammary artery and saphenous vein coronary bypass grafts. J Thorac Cardiovasc Surg. 1985;89:248-58.

19. Buxton BF, Ruengsakulrach P, Fuller J, Rosalion A, Reid CM, Tatoulis $\mathrm{J}$. The right internal thoracic artery graft-benefits of grafting the left coronary system and native vessels with a high grade stenosis. Eur J Cardiothorac Surg. 2000;18:255-61.

20. Hashimoto H, Isshiki T, Ikari Y, Hara K, Saeki F, Tamura T, et al. Effects of competitive blood flow on arterial graft patency and diameter. J Thorac Cardiovasc Surg. 1996;111:399-407.

21. Manninen HI, Jaakkola P, Suhonen M, Rehnberg S, Vuorenniemi R, Matsi PJ. Angiographic predictors of graft patency and disease progression after coronary artery bypass grafting with arterial and venous grafts. Ann Thorac Surg. 1998;66:1289-94.

22. Pagni S, Storey J, Ballen J, Montgomery W, Qaqish NK, Etoch S, et al. Factors affecting internal mammary artery graft survival: how is competitive flow from a patent native coronary vessel a risk factor? $J$ Surg Res. 1997;71:172-8.

23. Chardigny C, Jebara VA, Acar C, Descombes JJ, Verbeuren TJ, Carpentier A, et al. Vasoreactivity of the radial artery. Comparison with the internal mammary and gastroepiploic arteries with implications for coronary artery surgery. Circulation. 1993;88(Suppl):II115-27.

24. Possati C, Gaudino M, Alessandrini F, Luciani N, Glieca F, Trani C, et al. Midterm clinical and angiographic results of radial artery grafts used for myocardial revascularization. J Thorac Cardiovasc Surg. 1998;116:1015-21.

25. Borger MA, Cohen G, Buth KJ, Rao V, Bozinovski J, LiaghatiNasseri N, et al. Multiple arterial grafts: radial versus right internal thoracic arteries. Circulation. 1998;98(Suppl):II7-14.

26. Dietl $\mathrm{CA}$, Benoit $\mathrm{CH}$. Radial artery graft for coronary revascularization: technical considerations. Ann Thorac Surg. 1995;60:102-10.

27. Weinschelbaum EE, Gabe ED, Macchia A, Smimmo R, Suarez LD. Total myocardial revascularization with arterial conduits: radial artery combined with internal thoracic arteries. J Thorac Cardiovasc Surg. 1997;114:911-6.

28. Lytle BW, Loop FD, Thurer RL, Groves LK, Taylor PC, Cosgrove DM. Isolated left anterior descending coronary atherosclerosis: longterm comparison of internal mammary artery and venous autografts. Circulation. 1980;61:869-74.

\section{Discussion}

Dr Brian Buxton (Heidelberg, Australia). This article addresses the fundamental issue of how to best deploy valuable arterial grafts, and the authors analyzed a series of 109 patients with $\mathrm{T}$ or Y grafts; importantly, all these patients had sequential anastomoses. The authors conclude that patency appears sensitive to both location and degree of stenosis of the native artery, and they were concerned about the RCA grafting.

A very important message that comes from this article is that the study confirms the safety of using the left ITA and RA in a Y configuration, a concern to many of us. They found a low occlusion rate in the distal left ITA and proximal RA segment.

One of the problems when analyzing such an article is to isolate or identify the graft function from the many confounding variables in such a complex reconstruction. For instance, the RA, when used as a sequential Y graft, has 3 anastomoses and 2 segments, each having a separate pressure gradient. To try and unravel this problem, we examined, from our database, the patency of 191 free right ITA grafts and a separate series of 124 RA grafts used as a standard aorta-coronary rather than a sequential graft. However, we reached a very similar conclusion to those of the authors; that is, both of these arterial grafts had about a 3-fold increase in failure when anastomosed to vessels with a stenosis of less than $60 \%$ compared with those of $80 \%$ or greater. We also found that when the same arteries were grafted to the right coronary system, there was a 2 -fold increase in graft failure compared with grafting the left system.

The main point this article raises is that the patency of the segment of the RA distal to the sequential anastomosis is of concern. In a series of 336 RA graft angiograms performed by my colleagues, Dr Royse and Dr Tatoulis, we observed a 25\% graft failure in this situation in the first 12 months after reconstruction. In an attempt to overcome this problem, we now use the right skeletonized ITA in situ either with or without a radial graft used as an extension graft. This brings me to 2 questions I would like to ask the authors.

How did you manage grafting the distal RCA, and in view of the current information, how do you manage grafting a native vessel with a stenosis of about $50 \%$ when being considered as the sequential anastomosis?

Dr Maniar. Thank you, Dr Buxton, for your comments. In answer to your first question, grafts to the distal right coronary targets tend to have decreased patency regardless of conduit choice, either arterial or venous. The results of this investigation have shown that the RA is also at increased risk for occlusion when directed toward the right coronary distribution. As of yet, no prospective trials have been reported comparing RA patency with that of other conduits for this particular target. Because the ideal conduit for this target has yet to be established, we continue to use the RA conduit for critically stenosed targets of the RCA, accepting that the relative risk of occlusion is somewhat higher.

In terms of addressing a vessel with only moderate proximal stenosis, the question is a little more difficult. It appears that the RA is very sensitive to competitive flow. We believe that other conduits, including saphenous vein grafts, may be less sensitive to competitive flow, and as a result, we have recently adjusted our grafting strategy. We now limit the use of the RA for targets with at least $70 \%$ proximal stenosis or greater.

Your concern regarding the effect of sequential grafting is difficult to answer because over $90 \%$ of our patients in this analysis received sequential grafting. We therefore cannot separate out what role sequential grafting versus the biology of the RA graft might have played in RA occlusion.

Dr Todd Rosengart (Evanston, Ill). Coincidentally, we recently analyzed results of 80 patients undergoing postoperative angiography of some 4000 patients undergoing coronary artery bypass grafting at our institution. Interestingly, even in saphenous vein grafts we found that RCA anastomoses were a significant predictor of occlusion; however, we also found factors such as diabetes being the highest predictor of occlusion, with obesity also being a significant factor, but also risk factors such as graft quality playing an important role. Did you look at these factors, and if not, why not? Can you speculate at all about the reasons why, for example, RCA anastomoses tend to be a bigger problem not only in RAs but now also in saphenous veins?

Dr Maniar. It is interesting that you have similarly found decreased patency for targets of the RCA. We believe that one contributor to the inferior patency of the RCA may be that these targets supply a relatively smaller vascular bed in comparison with 
the LAD. Theoretically, the anastomoses to these targets do not receive the same benefit in terms of vascular outflow. This would not only affect the anastomotic patency of the RA but should also affect other arterial conduits and venous conduits alike.

With respect to your second question regarding patient profiles and comorbidities, we did address this and looked at several factors, including diabetes, hypertension, tobacco use, age, and sex. None of these was found to be a statistically significant predictor of anastomotic failure in our series.

Last, we did not include the quality of conduit in this analysis and cannot address this regarding its role as a possible risk factor for conduit patency.

Dr Sergio Moran (Santiago, Chile). In a very similar study, we found evidence supporting your results. We analyzed baseline and follow-up angiograms at 1 year postoperatively in patients submitted to myocardial revascularization with an RA graft. We found that the degree of stenosis in the native coronary artery significantly influences the patency of RA grafts. The patency in ITA grafts was $100 \%$ at 1 year, whereas RA patency was only $80 \%$. However, RA patency increased to $92 \%$ at 1 year when anastomosed to coronary arteries with $70 \%$ or greater stenosis. We did not find differences in the patency of RAs grafted to right or left coronary arteries. My question to you is, did you analyze the effect of calcium-channel antagonists in your results?

Dr Maniar. The current practice at our institution is not uniform with regard to the use of postoperative calcium-channel blockers. We have also found that in many instances the primary care physicians discontinue the calcium-channel blockers, often without our knowledge. As a result of the variability regarding postoperative use of calcium-channel blockers, we were unable to include this within our model or address the role these agents may play in RA graft patency.

Access to The Journal of Thoracic and Cardiovascular Surgery Online is reserved for print subscribers!

Full-text access to The Journal of Thoracic and Cardiovascular Surgery Online is available for all print subscribers. To activate your individual online subscription, please visit The Journal of Thoracic and Cardiovascular Surgery Online, point your browser to http://www.mosby.com/jtcvs, follow the prompts to activate your online access, and follow the instructions. To activate your account, you will need your subscriber account number, which you can find on your mailing label (note: the number of digits in your subscriber account number varies from 6 to 10). See the example below in which the subscriber account number has been circled:

\section{Sample mailing label}

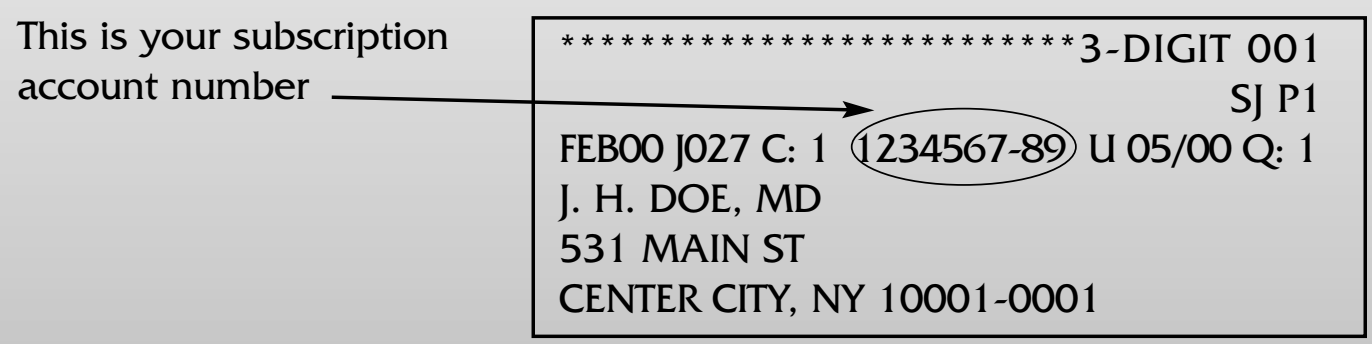

Personal subscriptions to The Journal of Thoracic and Cardiovascular Surgery Online are for individual use only and may not be transferred. Use of The Journal of Thoracic and Cardiovascular Surgery Online is subject to agreement to the terms and conditions as indicated online. 